\title{
RESISTÊNCIA À PENETRAÇÃO, EFICIÊNCIA DE ESCARIFICADORES MECÂNICOS E PRODUTIVIDADE DA SOJA EM LATOSSOLO ARGILOSO MANEJADO SOB PLANTIO DIRETO DE LONGA DURAÇÃO ${ }^{(1)}$
}

\author{
Vitor Caduro Girardello(2), Telmo Jorge Carneiro Amado ${ }^{(3)}$, Antônio Luis Santi ${ }^{(4)}$, \\ Maurício Roberto Cherubin ${ }^{(5)}$, Junior Kunz ${ }^{(6)}$ \& Tiago de Gregori Teixeira ${ }^{(6)}$
}

\begin{abstract}
RESUMO
Frequentemente, a compactação limita a produtividade das culturas anuais em solos mecanizados, sendo a sua distribuição na lavoura regionalizada. Em área manejada sob sistema plantio direto (SPD) por longo prazo, foi investigada a variabilidade espacial da resistência à penetração (RP), a eficiência de escarificadores mecânicos e o seu efeito na produtividade da soja. $O$ solo foi Latossolo Vermelho argiloso localizado no planalto do RS. O clima é subtropical Cfa com precipitação pluvial anual de $1.750 \mathrm{~mm}$ e temperatura média anual de $18,7^{\circ} \mathrm{C}$. O delineamento experimental foi de blocos casualizados com quatro tratamentos e duas repetições. Os tratamentos foram implantados em faixas paralelas de $100 \times 20 \mathrm{~m}$. Os tratamentos investigados foram: escarificador sítioespecífico com profundidade de atuação variada em razão da RP (ESEV); escarificador convencional (EC) com profundidade fixa; escarificador sítioespecífico com profundidade fixa (ESEF); e testemunha - sem escarificação (SE). Para avaliar a RP, utilizou-se um penetrômetro digital com leituras georrefenciadas em malha de $50 \times 50 \mathrm{~m}$ realizadas manualmente em duas épocas. A produtividade da soja foi obtida por meio de uma colhedora equipada com sensor de produtividade e antena receptora de sinal de GPS. A RP apresentou valores médios de 1,4 e 2,1 MPa, para leituras realizadas após o manejo da cultura de cobertura e após a colheita, respectivamente. A RP determinada após o manejo da cultura de cobertura e a
\end{abstract}

(1) Parte de Dissertação de Mestrado do primeiro autor, apresentado no Programa de Pós Graduação em Ciência do Solo, Universidade Federal de Santa Maria - UFSM. Recebido para publicação em 23 de março de 2013 e aprovado em 15 de abril de 2014.

(2) Doutorando em Engenharia Agrícola, UFSM. Av. Roraima, 1000. CEP 97105-900 Santa Maria (RS). Bolsista CAPES. E-mail: vitorgirardello@gmail.com

(3) Professor Titular, Departamento de Solos, UFSM. Bolsista CNPq. E-mail: telmo.amado@pq.cnpq.br

(4) Professor Adjunto, Departamento de Ciências Agronômicas e Ambientais, UFSM, campus de Frederico Westphalen. Linha Sete de Setembro, s/n. BR 386, km 40. CEP 98400-000 Frederico Westphalen (RS). E-mail: santi_pratica@yahoo.com.br

(5) Doutorando em Solos e Nutrição de Plantas, Escola Superior de Agricultura Luiz de Queiroz/USP. Av. Pádua Dias, 11. Caixa Postal 9. CEP 13418-900 Piracicaba (SP). E-mail: cherubin@usp.br

(6) Mestrandos em Ciência do Solo, UFSM. Bolsista CNPq. E-mail: junior_kunz@hotmail.com, tiagod.teixeira@gmail.com 
produtividade da soja apresentaram baixa correlação $\left(\mathrm{r}^{2}=-0,297 ; \mathrm{p}<0,05\right)$. Os valores de $\mathrm{RP}$ de 3,0 e 5,0 MPa resultaram em decréscimos de aproximadamente 10 e $38 \%$ na produtividade da soja, respectivamente. A escarificação mecânica, independentemente do equipamento utilizado, não incrementou a produtividade da soja em relação à testemunha. Esse resultado foi atribuído à $R P$ da área a ser classificada, quando da instalação dos tratamentos, como baixa/moderada, à ocorrência de frequente precipitação pluvial e às favoráveis condições físicohídricas proporcionadas pelo SPD de longa duração.

Termos de indexação: compactação do solo, agricultura de precisão, física do solo.

\section{SUMMARY: SOIL PENETRATION RESISTANCE, EFFICIENCY OF MECHANICAL CHISEL PLOWING AND SOYBEAN GRAIN YIELD IN A CLAYEY OXISOL UNDER LONG-TERM NO-TILL}

Frequently, soil compaction limits the yield of grain crops in mechanized lands, and its spatial distribution in the cropland is usually regionalized. In an area managed under longterm no-tillage, we investigated the relationship between soil penetration resistance $(P R)$ and soybean yield, the effectiveness of types of chisel plows, and their effect on soybean yield. The soil from the plateau region of the state of Rio Grande do Sul, Brazil, was classified as a clayey Oxisol. The climate is subtropical (Cfa - Köppen classification), with annual rainfall of 1,750 $\mathrm{mm}$ and mean annual temperature of $18.7^{\circ} \mathrm{C}$. A completely randomized block experimental design was used with four treatments and two replications. The treatments, arranged in parallel strips of $100 \times 20 \mathrm{~m}$, were: a) site-specific chisel plow with variable depth according to soil penetration resistance $(P R)(E S E V) ; b)$ conventional chisel plow $(E C)$ with fixed depth; c) sitespecific chisel plow with fixed depth (ESEF); d) control - without chisel plowing (SE). To evaluate $P R$, a digital penetrometer with georeferenced readings with a $50 \times 50 \mathrm{~m}$ grid was used, with two evaluation periods. Soybean grain yield was obtained through a combine equipped with a yield sensor and GPS satellite receiver. A mean value of 1.4 MPa was observed for RP after cover crop management practices and a mean value of 2.1 after harvest. The RP reading after cover crop management and soybean grain yield exhibited poor correlation $\left(r^{2}=-0.297 ; p<0.05\right)$. The PR values of 3.0 and $5.0 \mathrm{MPa}$ resulted in decreases of approximately 10 and $38 \%$ of soybean grain yields, respectively. Chisel plowing, regardless of the piece type of equipment used, did not increase soybean yield compared to the control without soil tillage. This result was attributed to the frequent rainfall and good physical and hydraulic conditions of long-term no-till.

Index terms: soil compaction, precision agriculture, soil physics.

\section{INTRODUÇÃO}

O solo é o produto de uma complexa interação de fatores pedogenéticos, que resulta na ocorrência da variabilidade espacial de seus atributos (Cantarutti et al., 2007). O manejo antrópico, visando à produção agrícola, também contribui para incrementar a variabilidade espacial de atributos (Santi et al., 2012).

O manejo sítio-específico é a base da agricultura de precisão (AP), que, segundo Blackmore et al. (1994), objetiva o aumento da eficiência do processo produtivo pelas intervenções agrícolas regionalizadas, que respeitam a variabilidade espacial de atributos de solo e de planta. Nesse caso, o conhecimento da variabilidade espacial dos atributos físico-hídrico do solo passa a ser relevante, a exemplo do que já ocorre tradicionalmente com os atributos químicos, que são investigados seguindo malha amostral georreferenciada.

A compactação em solos agrícolas sujeitos à mecanização intensiva frequentemente limita a produtividade das culturas (Hamza \& Anderson, 2005), especialmente sob condições de déficit hídrico (Klein \& Libardi, 2000; Richart et al., 2005). Geralmente, a compactação manifesta-se de forma regionalizada, com ocorrência mais severa nas zonas de maior frequência de trânsito de máquinas e equipamentos (Beutler et al., 2001; Amado et al., 2007). Essas zonas, geralmente, localizam-se nas extremidades da lavoura, diminuindo sua severidade em direção ao centro da área, ainda nos locais com maior umidade, ou com histórico de pressões recorrentes (zonas de manobras) (Silva et al., 2004). As plantas, em resposta à compactação do solo, apresentam alterações na profundidade, ramificação e distribuição das raízes (Rosolem et al., 2002), comprometendo a eficiência do uso de nutrientes e de água e limitando a produtividade da cultura (Alakukku \& Elomen, 1994).

Entre os atributos físicos com potencial para a detecção da variabilidade espacial da compactação do solo, na escala de lavoura comercial, destaca-se a RP (Tormena \& Roloff, 1996; Stone et al., 2002). A 
penetrometria, por gerar número de observações que permite elevada resolução espacial, bem como por ser rápida, economicamente viável e apresentar significado biológico, simulando o impedimento mecânico ao crescimento radicular, tem sido proposta como indicador da qualidade física do solo (Tavares Filho \& Tessier, 2009). Ainda, a RP, geralmente, apresenta maior relação com a produtividade das culturas do que com outros atributos físicos, como a densidade do solo e a porosidade total (Freddi et al., 2006).

Os valores de RP na faixa de 2,0 a 4,0 MPa têm sido propostos como críticos ao crescimento radicular de culturas anuais (Arshad et al., 1996; Suzuki et al., 2007), sendo seu efeito mais prejudicial quando o solo encontra-se com baixa umidade (Tavares Filho \& Tessier, 2009). Secco (2003), estudando o efeito do estado de compactação do solo em um Latossolo Vermelho distrófico, determinou que a RP na faixa de 2,65 a $3,26 \mathrm{MPa}$ proporcionou decréscimos na produtividade de trigo, milho e soja de 18,3; 34,0; e $24,3 \%$, respectivamente. Beutler et al. (2006) observaram, em um Latossolo Vermelho com $330 \mathrm{~g} \mathrm{~kg}^{-1}$ de argila, o decréscimo de $32 \%$ na produtividade da soja a partir de uma RP de 2,24 MPa.

Entre as alternativas para mitigar o efeito da compactação do solo às plantas, destaca-se a escarificação mecânica (Camara \& Klein, 2005). No entanto, a eficiência dessa prática no incremento da produtividade das culturas, em áreas manejadas sob SPD, tem sido controversa. Alguns trabalhos relataram que essa prática proporcionou o aumento de mais de $600 \mathrm{~kg} \mathrm{ha}^{-1}$ na produtividade do trigo sob Latossolo Vermelho (Klein et al., 2008). Entretanto, Secco et al. (2009) reportaram que mesmo sob diferentes níveis de compactação a escarificação mecânica não resultou no incremento da produtividade da soja em um Latossolo Vermelho distroférrico. Nicoloso et al. (2008) reportaram que a escarificação mecânica só foi eficiente no incremento da produtividade de culturas de grãos (soja, milho e trigo), quando associada ao uso de culturas de cobertura no inverno. Ainda, esses autores notaram que quando usada de forma isolada, antes da implantação da cultura de grãos, teve efeito efêmero na melhoria da qualidade física do solo, praticamente desaparecendo os benefícios quando as culturas atingiram o estádio reprodutivo, considerado o mais crítico para a produtividade de grãos. Portanto, embora a ocorrência de compactação nas lavouras mecanizadas seja frequentemente reportada na literatura nacional, ainda existem muitas dúvidas sobre a eficiência da escarificação em áreas manejadas sob SPD de longa duração.

No Brasil, há carência de trabalhos sobre a escarificação mecânica em macroparcelas, que contemplem a ocorrência de variabilidade espacial da compactação e da resposta das culturas, além de proporcionar o adequado funcionamento operacional do conjunto trator e implemento. Visando preencher essa lacuna, os objetivos deste trabalho foram: caracterizar a variabilidade espacial da $\mathrm{RP}$ em uma área comercial manejada sob o SPD por longo prazo; investigar a relação entre a $\mathrm{RP}$ e a produtividade da soja; e avaliar a eficiência de escarificadores mecânicos na redução da RP e no incremento da produtividade de grãos na cultura da soja.

\section{MATERIAL E MÉTODOS}

O estudo foi conduzido em área agrícola pertencente a um produtor associado à Cooperativa Agropecuária e Industrial (COTRIJAL), no município de Victor Graeff, RS, localizado nas coordenadas geográficas $28^{\circ} 31^{\prime} 40^{\prime \prime} \mathrm{S}$ e $52^{\circ} 40^{\prime} 18^{\prime \prime} \mathrm{O}$. A área investigada, que totaliza 50,6 ha, está sendo manejada sob SPD de forma contínua há 15 anos, tendo como principais culturas comerciais, durante a safra de verão, a soja (Glycine $\max (\mathrm{L}$.$) Merrill) e o milho (Zea mays L.),$ cultivados em rotação com proporção de dois anos da leguminosa para um ano da gramínea. No inverno, o trigo (Triticum aestivum L.) é cultivado antecedendo a soja; e a aveia-preta (Avena strigosa L.), o milho ou a soja, com proporção de dois anos com a cultura de cobertura para um com o cereal. O solo é classificado como Latossolo Vermelho distrófico (Santos et al., 2006), com relevo suavemente ondulado e textura argilosa (450 $\mathrm{g} \mathrm{kg}^{-1}$ de argila). Os teores de nutrientes do solo, quando da instalação do experimento, são apresentados no quadro 1.

O clima da região, segundo a classificação de Köppen, é do tipo Cfa subtropical (Nimer, 1989), com temperatura média anual de $18,7^{\circ} \mathrm{C}$. As chuvas são distribuídas regularmente em todos os meses do ano, com precipitação pluvial anual de $1.750 \mathrm{~mm}$.

A partir de 2005, a área investigada passou a ser acompanhada pelo Projeto Aquarius (www.ufsm.br/ projetoaquarius), sendo manejada com técnicas de agricultura de precisão visando a correção química do solo, por meio da taxa variada de corretivos e fertilizantes, e gerados mapas temáticos de produtividade com uma colhedora MF32 equipada com o sistema Fieldstar ${ }^{\circledR}$.

A colhedora utilizada na área experimental possuía pneus dianteiros com as especificações 18.4-34 RI e pneus traseiros tipo 14.9-24 R1, com pressão de insuflação de 20 psi e peso sem plataforma de colheita de $10.540 \mathrm{~kg}$. O trator utilizado possuía pneus dianteiros tipo 14.9-24 R1 e traseiro 18.4-34 R1 e pressão de insuflação de 16 psi e com peso de embarque lastrado de $5.240 \mathrm{~kg}$. O pulverizador foi o modelo Columbia (Jacto), com capacidade de $2.000 \mathrm{~L}$, peso de $1.055 \mathrm{~kg}$ e equipado com pneus tipo 9,5-24 RI.

Para a implantação do experimento, utilizou-se o mapa de produtividade da cultura do milho (2007/08), safra imediatamente anterior a do estudo, em que foram definidas três zonas de produtividade: zona de 
Quadro 1. Caracterização química e granulométrica do solo quando da implantação do experimento de um Latossolo Vermelho distrófico na camada de 0-0,15 m

\begin{tabular}{|c|c|c|c|c|c|c|c|c|c|c|}
\hline \multicolumn{2}{|c|}{$\mathbf{p H}$} & \multirow{2}{*}{$\operatorname{MOS}^{(1)}$} & \multirow{2}{*}{$\mathbf{P}^{(2)}$} & \multirow{2}{*}{$\mathbf{K}^{(2)}$} & \multirow{2}{*}{$\mathrm{Ca}^{(3)}$} & \multirow{2}{*}{$\mathbf{M g}^{(3)}$} & \multirow{2}{*}{$\mathrm{Al}^{(3)}$} & \multirow{2}{*}{$\mathrm{H}+\mathrm{Al}$} & \multirow{2}{*}{$\mathrm{V}^{(4)}$} & \multirow{2}{*}{$\operatorname{Argila}^{(5)}$} \\
\hline $\mathrm{H}_{2} \mathrm{O}$ & SMP & & & & & & & & & \\
\hline & & dag $\mathrm{kg}^{-1}$ & $-\mathrm{r}$ & 3 & 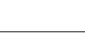 & $-\mathrm{cm}$ & -3 & & $\%$ & $\mathrm{~g} \mathrm{~kg}^{-1}$ \\
\hline 5,9 & 6,7 & 2,2 & 25,8 & 240 & 5,1 & 1,8 & 0,0 & 2,1 & 79 & 360 \\
\hline
\end{tabular}

(1) Matéria orgânica do solo; ${ }^{(2)} \mathrm{P}$ disponível e K trocável (Mehlich-1); ${ }^{(3)} \mathrm{Ca}, \mathrm{Mg}$ e Al trocáveis (KCl 1 mol L $\left.{ }^{-1}\right) ;{ }^{(4)}$ saturação por bases $\mathrm{e}^{(5)}$ teor de argila no solo.

alta produtividade (ZA) - com produtividade $>110 \%$ da média do talhão; zona de média produtividade (ZM) - com produtividade entre 90 e $110 \%$ da média do talhão; e zona de baixa produtividade (ZB) - com produtividade $<90 \%$ da média do talhão. O método utilizado neste estudo seguiu o utilizado por Amado et al. (2007).

Os blocos foram implantados nas zonas de baixa e média produtividades (ZB e ZM), onde haveria maior probabilidade de resposta à escarificação mecânica, uma vez que a produtividade nessas zonas tinha sido limitada. As escarificações foram realizadas em longas faixas paralelas, dispostas lado a lado em área homogênea, com dimensões de $100 \times 20 \mathrm{~m}$, totalizando uma área experimental de $16.000 \mathrm{~m}^{2}$. Experimentos em longas faixas são frequentes em estudos que envolvem máquinas agrícolas e tratamentos que podem ser influenciados pela variabilidade espacial de atributos de solo e planta (Carvalho et al., 2002; Molin et al., 2006). Os seguintes tratamentos foram investigados: escarificador sítio-específico com profundidade de atuação variada em razão da $R P$ (ESEV); escarificador convencional (EC); escarificador sítio-específico com profundidade fixa (ESEF); e testemunha - sem escarificação (SE). Na figura 1, apresenta-se a localização dos blocos na área agrícola. A RP foi determinada no mês de agosto de 2008, após o manejo da cultura de cobertura (aveia-preta) (RPCC), visando determinar a profundidade em que ocorre a RP máxima, além da umidade do solo. Para tanto, foi utilizada uma malha amostral regular de $50 \times 50 \mathrm{~m}$. Em cada ponto georreferenciado, foram realizadas 10 determinações de $\mathrm{RP}$ dentro de um raio de $3 \mathrm{~m}$ em relação o ponto central da quadrícula, totalizando 2.010 leituras. Já para definir a umidade do solo, utilizou-se a malha de $100 \times 100 \mathrm{~m}$. Nessa avaliação, foi utilizado um penetrômetro com armazenamento digital dos dados (PNT-2000), com ponta cônica de $30^{\circ}$ e com área do cone de $129 \mathrm{~mm}^{2}$, segundo as normas da ASAE (S.313.3), com registros a cada $0,01 \mathrm{~m}$ até $0,40 \mathrm{~m}$ de profundidade e com velocidade de penetração de aproximadamente $2 \mathrm{~m}$ min $^{-1}$. Com essas informações, foi possível gerar o mapa de prescrição da escarificação à profundidade variada, em razão da $R P$ utilizada no tratamento ESEV.

A escarificação mecânica foi realizada em novembro de 2008, uma semana antecedendo a semeadura da cultura da soja, quando o solo se encontrava com baixa umidade $\left(0,142 \mathrm{~kg} \mathrm{~kg}^{-1}\right)$. A cultivar da oleaginosa utilizada foi o BMX Apolo RR, de ciclo superprecoce e com espaçamento de $0,45 \mathrm{~m}$ entrelinhas e média de 12 sementes por $\mathrm{m}$ linear.

O escarificador sítio-específico (Fox ${ }^{\circledR}$, Stara) usado neste estudo foi recentemente lançado no mercado nacional, visando a utilização em SPD; possui nove hastes desencontradas, com espaçamento de 0,30 m. No chassi desse equipamento, foi instalado o sensor hidráulico-mecânico responsável por receber e transferir comandos, por meio de um sistema hidráulico, para o sensor responsável pelo acionamento do controle de profundidade. $\mathrm{Na}$ parte frontal do escarificador sítio-específico, há discos de corte de diâmetro de $400 \mathrm{~mm}$ posicionados na frente das hastes, visando o corte dos resíduos vegetais existentes na superfície do solo.

As hastes do escarificador sítio-específico distinguem-se das do EC, em razão da menor largura. Assim, as hastes desse equipamento possuem 0,03 m de largura e um ângulo em relação ao solo de $30^{\circ}$, caracterizando o modelo de haste reta. Além disto, a ponteira da haste é menor do que a do EC. Na parte posterior do escarificador, há um rolo destorroador com um diâmetro de $400 \mathrm{~mm}$. Esse rolo dispensou operações complementares de gradagem. A variação da profundidade de atuação do ESEV situou-se na faixa de 0,18 a $0,28 \mathrm{~m}$.

O equipamento utilizado no tratamento EC foi o Jumbo® (Jan), tradicionalmente usado no sistema de preparo convencional, com hastes escarificadoras tipo parabólica e ponteiras do tipo cinzel com 0,07 m de largura e $22^{\circ}$ de ângulo de ataque, com sete hastes espaçadas $0,40 \mathrm{~m}$. A profundidade de atuação de $0,30 \mathrm{~m}$ foi estabelecida por meio do sistema hidráulico e de duas rodas de aço fixadas no chassi. Esse modelo não possui discos frontais e rolos destorroadores na parte traseira do equipamento. Portanto, no tratamento EC, foi necessário uma operação complementar de grade leve antes da semeadura da soja.

O trator estava equipado com o monitor Falcon 3500 e com programa computacional que utilizava arquivos em formato VRC. A programação de profundidade de atuação do tratamento ESEV foi definida em razão do mapa de profundidade da $R P$ máxima. A precisão do sistema de controle de 


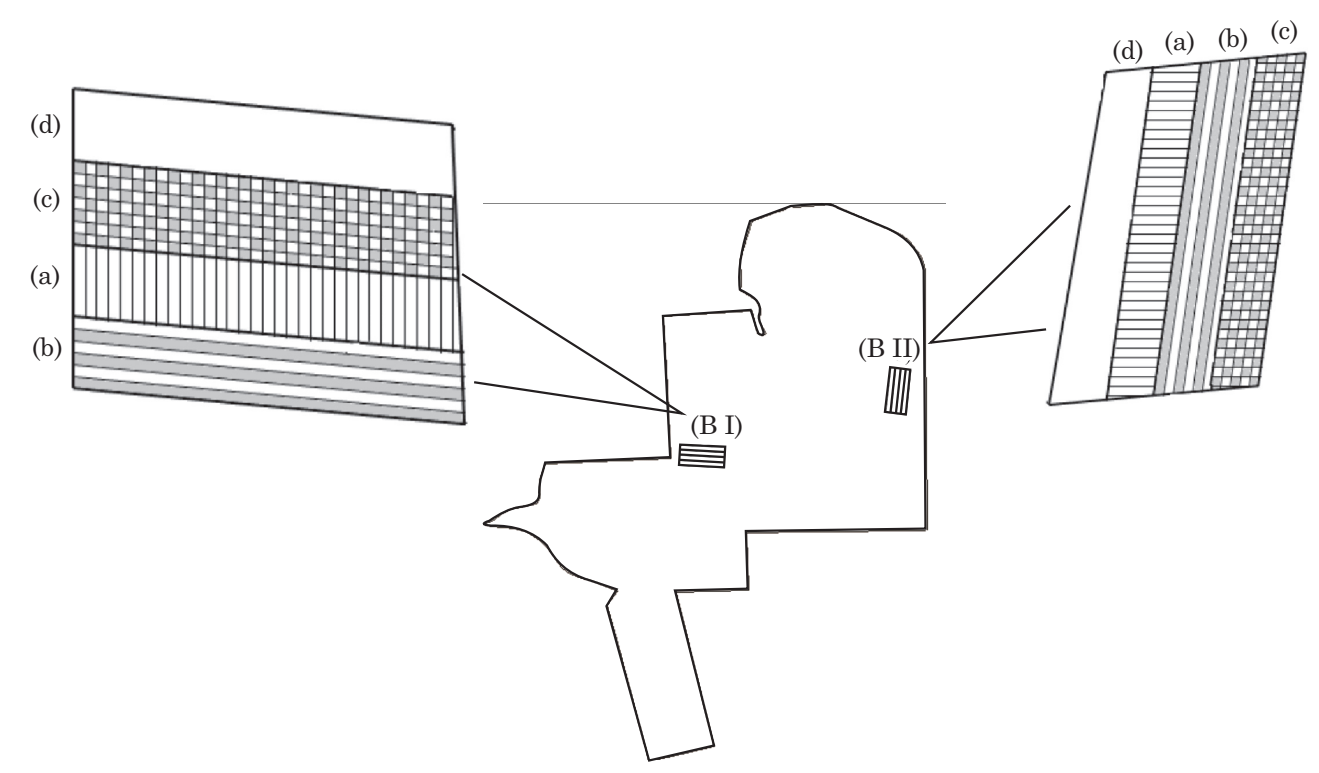

Figura 1. Localização espacial dos blocos e tratamentos na área experimental. Em que B I = Bloco I e B II = Bloco II. (a) EC = escarificador convencional; (b) ESEV = escarificador sítio-específico com profundidade de atuação variável; (c) ESEF = escarificador sítio-específico com profundidade de atuação fixa; e (d) $\mathrm{SE}=$ sem escarficação mecânica.

profundidade foi de $0,01 \mathrm{~m}$, sendo realizada a calibragem do sistema em área adjacente ao experimento. Na cabine do trator, foi instalada antena receptora DGPS (Tronick), associada ao monitor de controle das operações, visando o rastreamento da operação.

A RP foi determinada após a implantação dos tratamentos e anterior à semeadura da soja (RPSS), por meio de leituras espaçadas de $10 \mathrm{~m}$ entre si, totalizando 10 pontos por tratamento. Em torno de cada ponto, foram realizadas 10 repetições dentro de um raio de $3 \mathrm{~m}$, totalizando 100 leituras por tratamento. As determinações aconteceram quando o solo se encontrava com umidade de $0,142 \mathrm{~kg} \mathrm{~kg}^{-1}$.

Para determinar a produtividade da soja, utilizouse uma colhedora MF32 equipada com sensor de produtividade, GPS e conjunto Fieldstar ${ }^{\circledR}$. Cada faixa de tratamento foi colhida separadamente e pesada individualmente. Os dados de produtividade da soja foram tabulados, eliminando, pelas filtragens, as principais fontes de erros (Menegatti \& Molin, 2004). Para geração dos mapas temáticos, usou-se o programa CR-Campeiro 7 (Giotto et al., 2007). Os resultados de produtividade foram ajustados para $13 \%$ de umidade de grãos.

Após a colheita da soja, no mês de abril 2009, visando estabelecer a relação entre a $R P$ e a produtividade, em uma segunda época, foram realizadas leituras de RP (RPCS) em toda a área com malha de $50 \times 50 \mathrm{~m}$, seguindo as mesmas coordenadas geográficas e o mesmo método utilizado na primeira avaliação (RPCC).

A relação entre a $\mathrm{RP}$ e a produtividade da cultura da soja foi obtida pela sobreposição dos mapas. Para tanto, utilizou-se um raio de busca de $7 \mathrm{~m}$ em torno de cada ponto amostral de RP, nas duas épocas avaliadas, visando obter o valor de produtividade correspondente ao ponto de RP. Posteriormente, os dados foram distribuídos em classes com intervalo de 0,5 MPa de RP e classificados, conforme Arshad et al. (1996) em: muito baixa: 0,01 $\leq \mathrm{RP}<0,1 \mathrm{MPa}$; baixa: $0,1 \leq \mathrm{RP}<1,0 \mathrm{MPa}$; moderada: $1,0 \leq \mathrm{RP}<2,0 \mathrm{MPa}$; alta: $2,0 \leq \mathrm{RP}<4,0 \mathrm{MPa}$; muito alta: $4,0 \leq \mathrm{RP}<8,0$ $\mathrm{MPa}$; e extremamente alta: $\mathrm{RP}>8,0 \mathrm{MPa}$.

O delineamento experimental foi de blocos casualizado com quatro tratamentos e duas repetições. A análise estatística descritiva foi utilizada para obtenção dos seguintes parâmetros: mínimo, média, máximo, variância, desvio-padrão, coeficientes de variação, assimetria e curtose. Ainda, efetuou-se o teste de Shapiro-Wilk $(\mathrm{p}>0,05)$ para verificar a normalidade dos dados. O programa computacional utilizado foi o SISVAR 5.0 (Ferreira, 2007). As médias foram comparadas pelo teste de Tukey $(p<0,05)$ para se determinar a relação entre a RP e a produtividade de soja.

\section{RESULTADOS E DISCUSSÃO}

\section{Relação da resistência à penetração do solo com a produtividade da soja}

No período experimental, a precipitação pluvial acumulada durante o ciclo da cultura da soja foi de $560 \mathrm{~mm}$ (Figura 2), resultando em uma precipitação média de $4 \mathrm{~mm}$ dia $^{-1}$, quantidade suficiente para atender a demanda de evapotranspiração, na maioria 
dos estádios fenológicos da cultura. Nenhum evento de precipitação ultrapassou os $40 \mathrm{~mm} \mathrm{dia}^{-1}$, fato que favoreceu a infiltração e o armazenamento de água no solo; entretanto, desfavoreceu a ocorrência da enxurrada.

O mapa de produtividade da cultura da soja, na safra investigada apresenta-se na figura 3a. A produtividade média da soja na área agrícola foi de $3.630 \mathrm{~kg} \mathrm{ha}{ }^{-1}$, com $59 \%$ da área apresentando produtividade na faixa de 3.500 a $4.200 \mathrm{~kg} \mathrm{ha}^{-1}$. Essa produtividade é $39,3 \%$ superior à média estadual na respectiva safra. A elevada produtividade de soja alcançada, neste estudo, foi explicada pelas frequentes precipitações durante o ciclo da cultura (Figura 2), pela elevada fertilidade do solo na média geral da área (Quadro 1), pela melhoria na qualidade do solo, pelo período de tempo de adoção do SPD e pelo cultivar da soja utilizado, que possui elevado potencial produtivo.

A espacialização da RP na área agrícola foi realizada após o manejo da cultura de cobertura (Figura 3b) e posterior à colheita da soja (Figura 3c). Na primeira avaliação, $72 \%$ da área apresentavam valores de $\mathrm{RP}$ inferior a $1,5 \mathrm{MPa}$; e $52 \%$, como baixo $(<1,0 \mathrm{MPa})$ (Arshad et al., 1996) (Figura 3b). Esses baixos valores da RP, provavelmente, foram por causa do efeito positivo do sistema radicular da aveia-preta na melhoria da estrutura do solo (Nicoloso et al., 2008). Já na determinação da RP, realizada após a colheita da soja, foi observado um incremento da RP, que apresentou valor médio de 2,1 MPa, sendo próximo ao valor crítico proposto por Tormena et al. (1998) e Reichert et al. (2003). Além disso, destaca-se que $47 \%$ da área ainda apresentava $\mathrm{RP}<2,0 \mathrm{MPa}$ e que menos de $5 \%$ da área evidenciava $\mathrm{RP}>3,0 \mathrm{MPa}$, sendo os valores elevados localizados nas extremidades do talhão, onde estão mais sujeitas a manobras de máquinas agrícolas. Os valores de RP classificados como moderado a baixo predominantes na área suportam a elevada produtividade de soja alcançada.

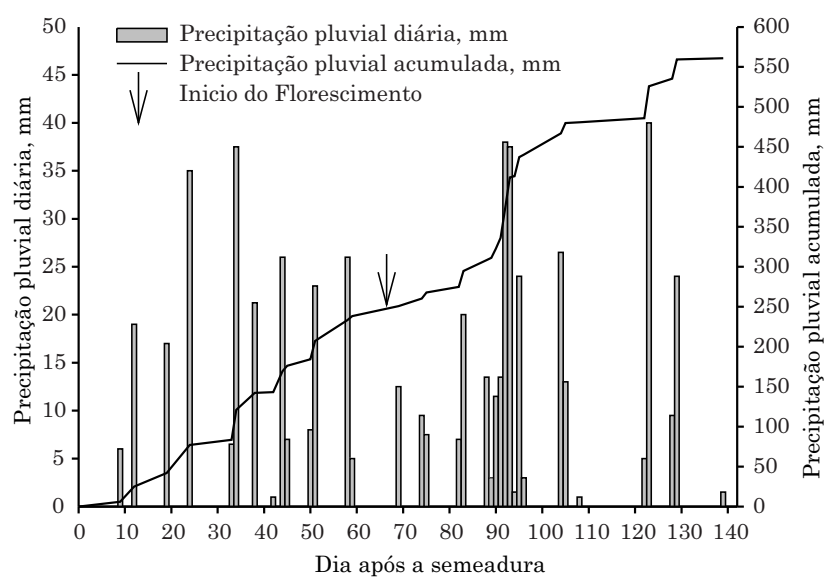

Figura 2. Precipitação pluvial diária e acumulada durante o ciclo da cultura da soja no ano agrícola 2008/09, no município de Victor Graeff, RS. Fonte: Cotrijal.
Quanto à distribuição espacial da produtividade da soja e da RP, observou-se que a noroeste, canto superior direito da área, houve correspondência da menor produtividade de soja com valores mais elevados desse atributo físico (Figura 3a,c). No sudoeste, observou-se uma zona com elevada produtividade de soja (> $4.200 \mathrm{~kg} \mathrm{ha}^{-1}$ ) (Figura 3a), que foi coincidente com a ocorrência de RP classificada como baixa, para a determinação realizada após o manejo da cultura de cobertura (Figura 3b) e, como média, para leitura realizada após a colheita de soja (Figura 3c). Ainda, constatou-se que as áreas com maior valor de RP concentram-se espacialmente nas extremidades da lavoura, notadamente a noroeste, provavelmente em razão do frequente trânsito de máquinas agrícolas nas operações de carga e descarga de produtos. Anteriormente, Silva et al. (2004) também reportaram maior severidade da compactação na extremidade das lavouras, decrescendo em direção ao centro delas.

A representação espacial da produtividade da soja e da RP, por meio do SIG, foi uma estratégia eficiente em determinar locais críticos quanto à compactação. Essa informação pode ser utilizada no planejamento agrícola, evitando-se a concentração de operações e trânsito de máquinas agrícolas nessas zonas e, em casos mais severos, pode-se ainda utilizar a escarificação sítio-específica, restringindo-a a esses locais, evitando gastos energéticos e impactos ambientais desnecessários (Girardello et al., 2011).

A relação entre a $\mathrm{RP}$ e a produtividade da soja em área agrícola manejada sob SPD de longa duração é apresentada no quadro 2 . Nesse caso, foi utilizado um conjunto de 201 pontos de RP e de produtividade de soja, em cada uma das épocas de amostragem avaliadas. Para leituras de RPCC, realizadas após o manejo da cultura de cobertura e antes da semeadura da soja, a relação foi de $r^{2}=-0,297(p<0,05)$. Já para leitura de RPCS, após a colheita da soja, não houve relação com a produtividade da oleaginosa. Ainda, na avaliação da RPCC, a umidade do solo foi de $0,142 \mathrm{~kg} \mathrm{~kg}^{-1}$; e para RPCS, de 0,204 $\mathrm{kg} \mathrm{kg}^{-1}$. Neste estudo, observou-se a relação significativa positiva $\left(r^{2}=0,236 ; p<0,05\right)$ entre a RPCC e a RPCS, sugerindo que o aumento da $R P$ verificado após a cultura da soja ocorreu preferencialmente nas áreas que já apresentavam maior RP antes da semeadura (Quadro 2). Roque et al. (2008) reportaram relação significativa $\left(r^{2}=-0,136 ; p<0,05\right)$ entre a RP e a produtividade de feijão. Já Dalchiavon et al. (2011), em um experimento conduzido sob SPD no Cerrado, reportaram que a produtividade da cultura da soja se relacionou significativamente com a RP, com $\mathrm{r}^{2}=-0,219(\mathrm{p}<0,05)$. Esse último valor foi semelhante ao reportado neste trabalho. Assim, os valores da relação entre a RP e a produtividade de soja, em geral, têm sido baixos, especialmente quando o estudo é conduzido sob condições de precipitação frequente e em quantidade suficiente para atender plenamente a demanda da cultura. 
As leituras de RPCC, que apresentaram relação significativa com a produtividade de soja (Quadro 2), foram classificadas em classes, de acordo com Arshad et al. (1996) (Figura 4). Nesse caso, as maiores produtividades de soja, conforme esperado, foram obtidas sob RP classificada como baixa/moderada. Já para $\mathrm{RP}=3,0 \mathrm{MPa}$, a redução na produtividade, com base na equação ajustada, foi de $10 \%$. Ainda, com o aumento da RP para 4,0 MPa, que é classificada como muito alta, a redução foi de $32 \%$; e finalmente com $\mathrm{RP}$ de 5,0 $\mathrm{MPa}$ o decréscimo alcançou $38 \%$, correspondendo a uma perda de $1.436 \mathrm{~kg} \mathrm{ha}^{-1}$. Assim, neste estudo, sugere-se o valor de RP de 3,0 MPa como crítico. Em estudos da área da fertilidade do solo, geralmente considera-se que uma redução do rendimento relativo de $10 \%$ é critério para definir o teor crítico de nutrientes, sugerindo elevada probabilidade de resposta à fertilização (CQFSRS/SC, 2004).

O valor crítico de RP para a cultura da soja pode ser influenciado pelo sistema de manejo, rotação de culturas, e, especialmente, tipo de solo (Beutler et al., 2004). Reichert et al. (2003) propuseram o valor crítico de 2,0 MPa para a cultura da soja. Analogamente, Klein \& Camara (2007), por meio do intervalo hídrico ótimo (IHO), em um Latossolo, reportaram o valor de 3,0 $\mathrm{MPa}$, como sendo associado ao ponto de murcha permanente da cultura da soja. Esse último resultado concorda com os obtidos neste estudo.

Santi et al. (2012), investigando zonas de baixa produtividade de grãos em Latossolo Vermelho,

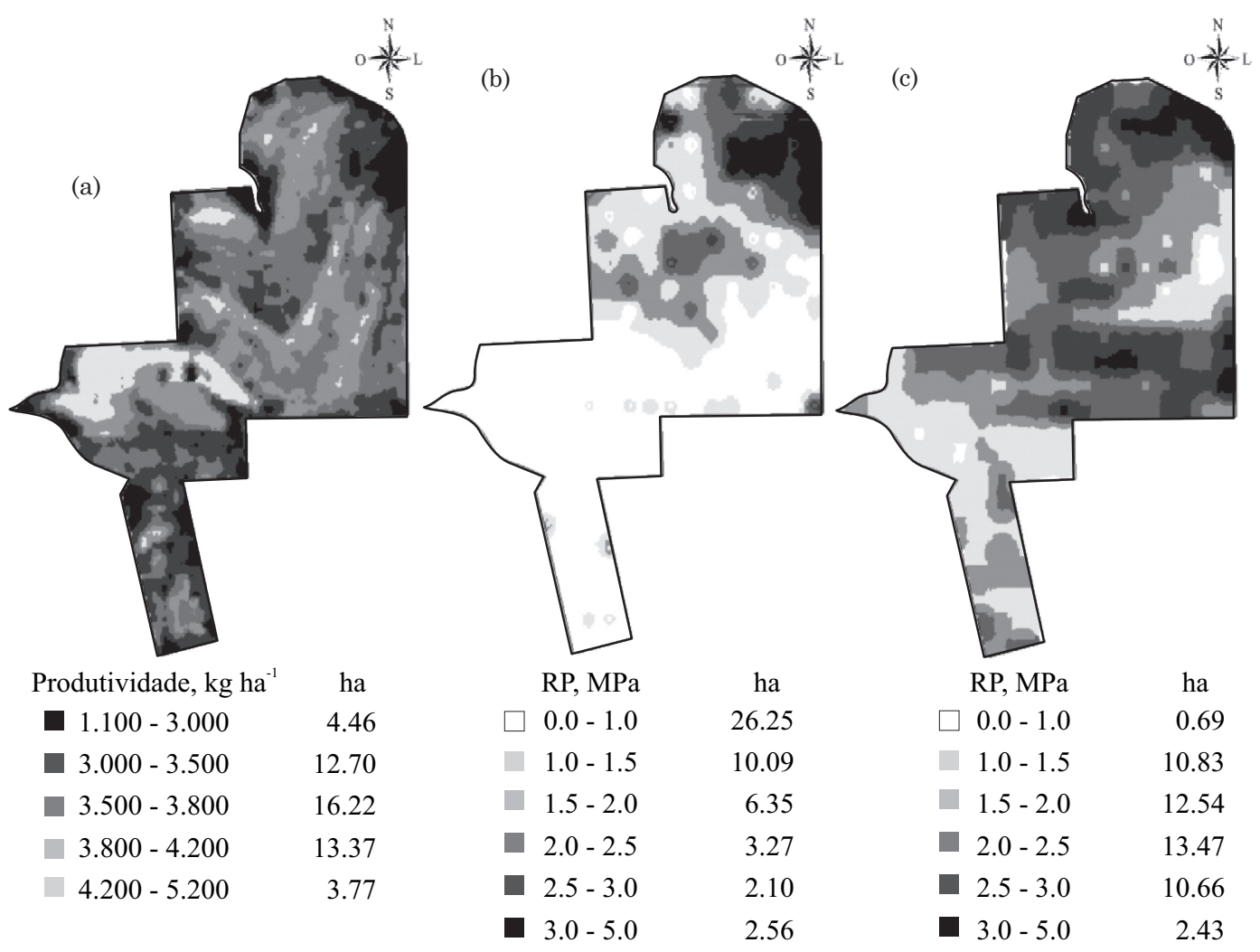

Figura 3. Produtividade da cultura da soja na safra de 2008/09 (a), resistência máxima à penetração (RP) determinada por penetrômetro digital após o manejo da cultura de cobertura (b) e determinada após a colheita da soja (c) em Latossolo Vermelho.

Quadro 2. Relação entre a resistência do solo à penetração determinada em duas épocas e a produtividade da soja em área agrícola comercial na safra de 2008/09, em Latossolo Vermelho

\begin{tabular}{|c|c|c|c|}
\hline & Produtividade da soja & $\operatorname{RPCC}^{(1)}$ & $\operatorname{RPCS}^{(2)}$ \\
\hline Produtividade da soja & 1 & & \\
\hline $\mathrm{RPCC}$ & $-0,297^{*}$ & 1 & \\
\hline RPCS & $0,018^{\mathrm{ns}}$ & $0,236^{*}$ & 1 \\
\hline $\mathrm{N}^{\mathrm{o}}$ de observações & 201 & 201 & 201 \\
\hline
\end{tabular}

(1) RPCC: resistência do solo à penetração após manejo da cultura de cobertura; ${ }^{(2)}$ RPCS: resistência do solo à penetração depois da colheita da soja; ${ }^{\text {ns }}$ não significativo; ${ }^{*}$ significativo $(p<0,05)$. 


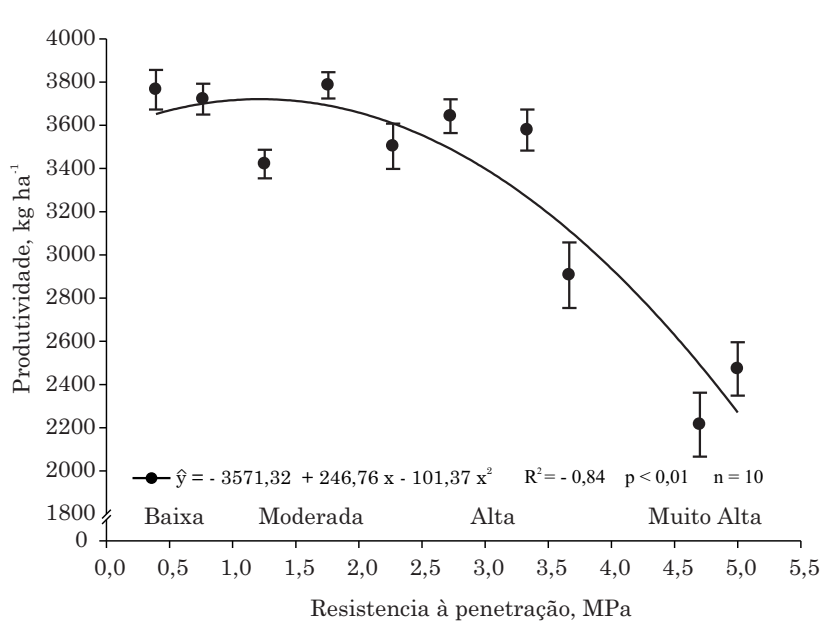

Figura 4. Produtividade da cultura da soja em função da resistência da penetração, determinada após o manejo da cultura de cobertura e classificada de acordo com Arshad et al. (1996), em Latossolo Vermelho na safra de $2008 / 09$, muito alta.

reportaram que o decréscimo da infiltração, induzido pela compactação, foi o principal responsável pela limitação da produtividade das culturas. Amado et al. (2007) encontraram que a zona de baixa produtividade apresentava as características de maior RP, menor macroporosidade e menor capacidade de água disponível no solo, em relação à zona de alta produtividade. O decréscimo na produtividade de soja sob elevadas RP também pode estar associado a modificações morfológicas das raízes, com decréscimo na divisão celular e aumento do seu diâmetro, além de estimular o desenvolvimento de raízes mais finas, com menor capacidade de romper a camada compactada (Richart et al., 2005), reduzindo o volume de solo explorado e, consequentemente, a absorção de água e nutrientes (Taylor \& Brar, 1991).

\section{Eficiência dos escarificadores mecânicos no decréscimo da RP}

A eficiência dos escarificadores foi avaliada por meio do experimento, envolvendo quatro tratamentos (Figura 1). Após a escarificação mecânica, independentemente do tipo de escarificador investigado, observou-se decréscimo dos valores de RP em relação à testemunha (Figura 5). No momento da realização da escarificação mecânica, a umidade do solo era de $0,172 \mathrm{~kg} \mathrm{~kg}^{-1}$. No tratamento SE a RP foi classificada como moderada, com valores médios de $1,36 \mathrm{MPa}$ (Figura 5).

Um dos principais objetivos da escarificação mecânica é diminuir a RP do solo e isso foi alcançado, em ambos os blocos, independentemente do tipo de escarificador. Assim, após a escarificação mecânica, indiferentemente do tipo de equipamento utilizado, praticamente não se verificaram mais valores de $R P$ na faixa de 1,3 a 1,6 MPa, ao longo da faixa investigada
(Figura 5). No Bloco I, a RP média do tratamento SE foi 1,46 MPa e no tratamento EC, 1,07 MPa; portanto, a escarificação mecânica reduziu em $27 \%$ a RP média. Entretanto, no Bloco II, a RP média do SE foi $1,27 \mathrm{MPa}$, e no tratamento ESEF, 0,63 $\mathrm{MPa}$, com redução de 50 \%. Anteriormente, Klein \& Camara (2007), avaliando o efeito de escarificador mecânico em Latossolo, também reportaram decréscimo na $\mathrm{RP}$.

\section{Produtividade da soja}

A análise de variância do experimento de eficiência dos escarificadores apresenta-se no quadro 3. Nesse caso, não houve incremento da produtividade da soja em razão da escarificação mecânica, independentemente do tipo de escarificador investigado. Realizou-se a avaliação do desempenho dos escarificadores em relação à produtividade da soja sob condições de solo com RP classificada como abaixo do valor crítico e com precipitação, durante o ciclo da cultura da soja, considerada como satisfatória (Figura 2).

A produtividade média da soja no experimento foi de $3.669 \mathrm{~kg} \mathrm{ha}^{-1}$, sendo semelhante à média de produtividade de toda a área agrícola, que foi de $3.630 \mathrm{~kg} \mathrm{ha}^{-1}$ (Quadro 4). Portanto, os resultados reportados no experimento refletiram o padrão de resposta da cultura da soja às condições de solo, clima e manejo do talhão investigado. A ausência de incremento da produtividade pelo uso de escarificadores pode estar associada às características da soja, que é considerada uma cultura rústica que sob condições climáticas favoráveis apresenta limitada resposta a intervenções no solo (Pivetta et al., 2011). Anteriormente, Amado et al. (2007), comparando mapas de produtividade de soja e de milho, relataram que a primeira cultura é menos sensível à qualidade do solo em relação à segunda, especialmente sob condições de precipitação elevada.

Em um Latossolo Vermelho, Secco et al. (2005) avaliaram o efeito da escarificação mecânica em diferentes culturas. Esses autores reportaram que a produtividade das culturas da soja, do trigo e do milho não foi incrementada pela escarificação do solo realizada no outono, antecedendo à semeadura, à semelhança do realizado neste estudo. De maneira análoga, Klein \& Camara (2007) também não encontraram incremento na produtividade da soja em um Latossolo com estado de compactação do solo inicial baixo. Ainda, Centurion \& Demattê (1992), em um estudo realizado com milho, relataram que a produtividade não foi influenciada pela escarificação mecânica, atribuindo o resultado à frequente precipitação que contribuiu para manter elevada a umidade do solo. Esses resultados suportam que, sob condições físico-hídricas não limitantes ao desenvolvimento vegetal, a escarificação mecânica do SPD é uma prática dispensável.

A ausência de diferença na produtividade de soja submetida a diferentes tipos de escarificadores era esperada, uma vez que não houve diferença dos 


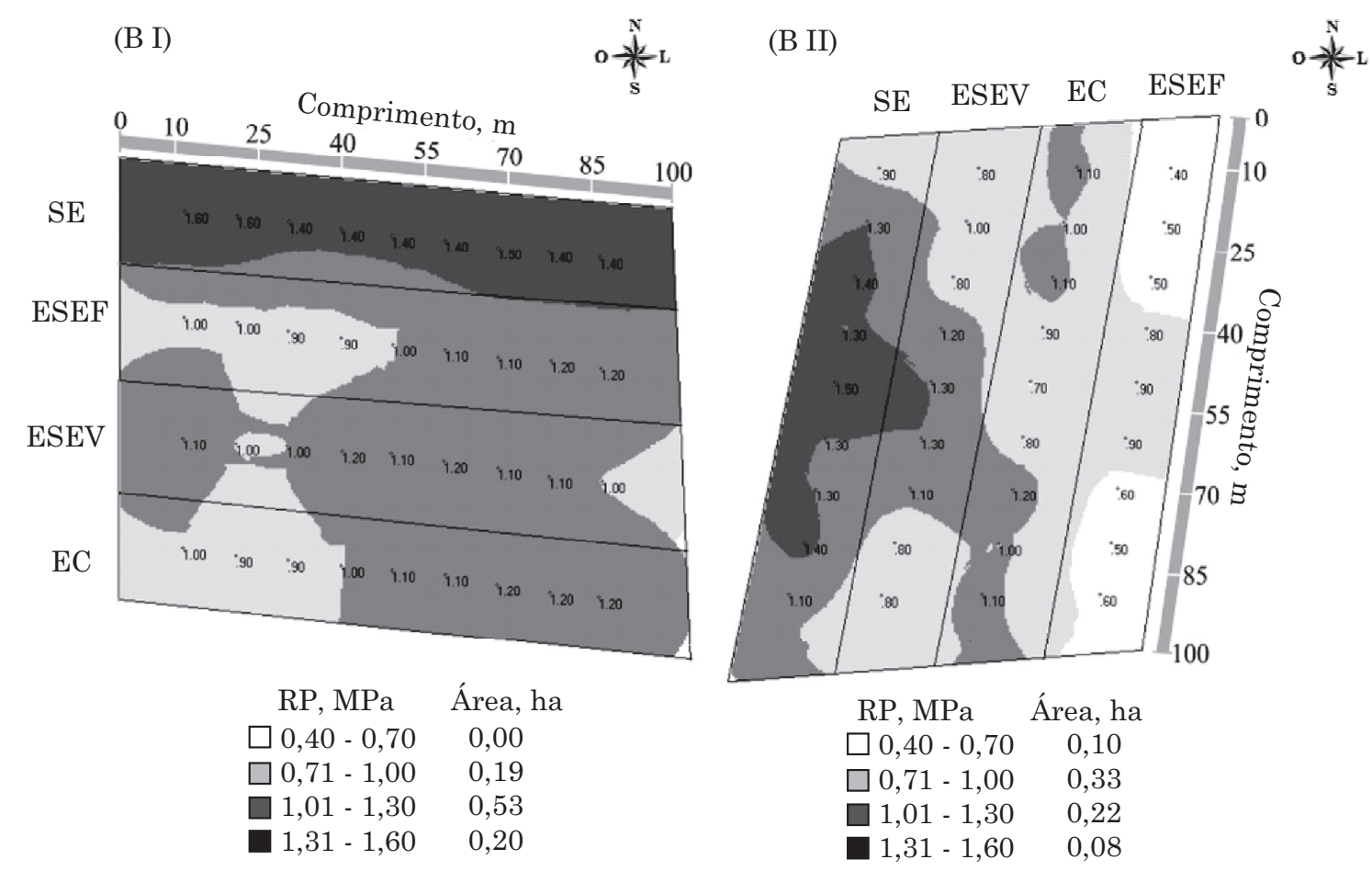

Figura 5. Variabilidade espacial da resistência à penetração do solo, determinada logo após a escarificação mecânica, nos dois blocos em que, (B I) = bloco I e (B II) bloco II. RP: resistência à penetração; EC: escarificador convencional; ESEV: escarificador sítio-específico com profundidade de atuação variável; ESEF: escarificador sítio-específico com profundidade de atuação fixa; e SE: sem escarificação mecânica.

Quadro 3. Análise de variância do experimento de eficiência de escarificadores mecânicos na produtividade da cultura da soja

\begin{tabular}{lrrrrr}
\hline Causa da variação & GL & SQ & QM & Fc & Pr> Fc \\
\hline Bloco & 1 & 19180,56 & 19180,56 & $0,53^{\text {ns }}$ & $1,20^{\text {ns }}$ \\
Tratamento & 3 & 128712,53 & 42904,17 & & 9,27 \\
Resíduo & 3 & 106846,82 & 35615,60 & & \\
Total & 7 & 254739,93 & & \\
CV (\%) & 5,1 & & & \\
\hline
\end{tabular}

${ }^{n s}$ não significativo a $5 \%$, pelo teste $\mathrm{F}$.

Quadro 4. Produtividade de soja nos tratamentos investigados

\begin{tabular}{|c|c|c|c|c|c|c|c|c|}
\hline \multirow{2}{*}{ Tratamento $^{(1)}$} & \multicolumn{3}{|c|}{ Produtividade da soja } & \multirow{2}{*}{$\mathrm{DP}^{(2)}$} & \multicolumn{3}{|c|}{ Coeficiente $^{(3)}$} & \multirow{2}{*}{ Teste $\mathrm{W}^{(4)}$} \\
\hline & Média & Mínimo & Máximo & & CV & Cs & $\mathbf{C k}$ & \\
\hline & 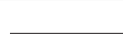 & $-\mathrm{kg} \mathrm{ha}^{-1}$ & 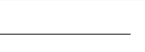 & & $\%$ & & & \\
\hline ESEV & $3.761^{\mathrm{ns}}$ & 2.800 & 4.200 & 396,6 & 9,8 & $-1,56$ & 2,81 & $0,85 \mathrm{NN}$ \\
\hline ESEF & 3.437 & 2.660 & 3.925 & 314,4 & 9,1 & $-0,80$ & 1,44 & $0,93 \mathrm{~N}$ \\
\hline $\mathrm{EC}$ & 3.790 & 2.839 & 4.287 & 382,2 & 10,4 & $-1,12$ & 1,31 & $0,92 \mathrm{~N}$ \\
\hline SE & 3.688 & 2.827 & 4.140 & 393,4 & 10,6 & $-1,23$ & 0,56 & $0,84 \mathrm{NN}$ \\
\hline Média do experimento & 3.699 & 2.666 & 4.287 & 391,9 & 10,2 & $-0,83$ & 0,11 & $0,93 \mathrm{~N}$ \\
\hline Média da área agrícola & 3.630 & 2.118 & 4.957 & 483,8 & 13,4 & $-0,48$ & 1,18 & $0,96 \mathrm{~N}$ \\
\hline
\end{tabular}

(1) ESEF: escarificador sítio-específico em profundidade fixa; ESEV: escarificador sítio-específico em profundidade variada; EC: escarificador convencional; e SE = controle sem escarificação. ${ }^{(2)} \mathrm{DP}$ : desvio-padrão; ${ }^{(3)} \mathrm{CV}$ : coeficiente de variação; Cs: coeficiente de assimetria; Ck: coeficiente de curtose. ${ }^{(4)}$ Teste W: teste de Shapiro-Wilk para distribuição normal; N: normal; e NN: não normal. ${ }^{n s}$ não significativo pelo teste de Tukey $(\mathrm{p}<0,05)$. 
tratamentos com escarificação em relação à testemunha (Quadro 4). Anteriormente, Girardello et al. (2011) reportaram que o EC ocasionou maior alteração nas propriedades físicas no solo, quando comparado ao escarificador sítio-específico, resultando, em curto prazo, em maior infiltração de água e menor densidade do solo. Já o escarificador sítio-específico proporcionou, naquele estudo, maior manutenção da cobertura vegetal na superfície do solo, fato que é importante para reduzir a evaporação e diminuir a temperatura do solo (Oliveira et al., 2005).

\section{CONCLUSÕES}

1. A utilização de mapas temáticos da resistência à penetração e da produtividade de soja, por meio do SIG, foi uma estratégia eficiente para determinar a espacialização de áreas com elevada resistência à penetração, subsidiando a intervenção localizada.

2. $\mathrm{O}$ valor crítico de resistência à penetração do Latossolo Vermelho foi de 3,0 MPa, induzindo decréscimo de $10 \%$ na produtividade da soja. A partir do valor crítico, pequenos incrementos na resistência à penetração ocasionaram acentuado decréscimo na produtividade da oleaginosa, alcançando redução de $38 \%$ com 5,0 MPa.

3. A escarificação mecânica não incrementou a produtividade de soja, em relação ao tratamento sem escarificação, em solo manejado sob sistema plantio direto com resistência à penetração, classificada como baixa/moderada e em condições de elevada precipitação.

\section{LITERATURA CITADA}

ALAKUKKU, L. \& ELOMEN, P. Long-term effects of a single compaction by heavy field traffic on yield and nitrogen uptake of annual crops. Soil Till. Res., 36:141-152, 1994.

AMADO, T.J.C.; PONTELLI, C.B.; SANTI, A.L.; VIANA, J.H.M. \& SULZBACH, L. Variabilidade espacial e temporal da produtividade de culturas sob sistema plantio direto. Pesq. Agropec. Bras., 42:1101-1110, 2007

ARSHAD, M.A.; LOWERY, B. \& GROSSMAN, B. Physical tests for monitoring soil quality. In: DORAN, J.W. \& JONES, A.J., eds. Methods for assessing soil quality. Madison, Soil Science Society of America, 1996. p.123141.

BEUTLER, A.N.; SILVA, M.L.; CURI, N.; FERREIRA, M.M.; CRUZ, J.C. \& PEREIRA FILHO, I.A. Resistência à penetração e permeabilidade de Latossolos Vermelhos distrófico típico sob o sistema de manejo na região dos cerrados. R. Bras. Ci. Solo, 25:167-177, 2001.

BEUTLER, A.N.; CENTURION, J.F. \& SILVA, A.S. Intervalo hídrico ótimo e a produção da soja e arroz em dois Latossolos. Irriga, 9:181-192, 2004.
BEUTLER, A.N.; CENTURION, J.F.; CENTURION, M.A.P.C. \& SILVA, A.P. Efeito da compactação na produtividade de cultivares de soja em Latossolo Vermelho. R. Bras. Ci. Solo, 30:787-794, 2006.

BLACKMORE, B.S.; WHEELER, P.N. \& MORRIS, R.M. The role of precision farming in sustainable agriculture: A european perspective. Minneapolis, 1994. 13p.

CAMARA, R.K. \& KLEIN, V.A. Propriedades físico-hídricas do solo sob plantio direto escarificado e rendimento da soja. Ci. Rural, 35:813-819, 2005

CANTARUTTI, R.B.; BARROS, N.F.; MARTINEZ, H.E.P. \& NOVAIS, R.F. Avaliação da fertilidade e recomendação de fertilizantes. In: NOVAIS, R.F.; ALVAREZ V., V.H.; BARROS, N.F.; FONTES, R.L.F.; CANTARUTTI, R.B. \& NEVES, J.C.L., eds. Fertilidade do solo. Viçosa, MG, Sociedade Brasileira de Ciência do Solo, 2007. p.769-850.

CARVALHO, M.P.; SORATO, R.P. \& ONÃ, F.S. Variabilidade espacial de atributos físicos em um Latossolo Vermelho distrófico sob preparo convencional em Selvíria, Estado de Mato Grosso do Sul. Acta Sci., 24:1353-1361, 2002.

CENTURION, J.F. \& DEMATTÊ, J.L.I. Sistema de preparo de solos de cerrado: Efeitos nas propriedades físicas e na cultura do milho. Pesq. Agropec. Bras., 27:315-324, 1992.

COMISSÃO DE QUÍMICA E FERTILIDADE DO SOLO . CQFS-RS/SC. Manual de adubação e calagem para os estados do Rio Grande do Sul e Santa Catarina. Porto Alegre, Sociedade Brasileira de Ciência do Solo/Núcleo Regional Sul, 2004. 400p.

DALCHIAVON, F.C.; CARVALHO, M.P.; NOGUEIRA, D.C.; ROMANO, D.; ABRANTES, F.L.; ASSIS, J.T. \& OLIVEIRA, M.S. Produtividade da soja e resistência mecânica à penetração do solo sob sistema plantio direto no cerrado brasileiro. Pesq. Agropec. Trop., 41:8-19, 2011.

FERREIRA, D.F. Programa SISVAR.exe: Sistema de análise de variância. Lavras, Universidade Federal de Lavras, 2007.

FREDDI, O.S.; CARVALHO, M.P.; VERONESI JÚNIOR, V. \& CARVALHO, G.J. Produtividade do milho relacionada com a resistência mecânica à penetração do solo sob preparo convencional. Eng. Agríc., 26:113-121, 2006.

GIOTTO, E.; ROBAINA, A.D. \& SULZBACH, L. A agricultura de precisão com o CR Campeiro 7. Manual do usuário. Santa Maria, UFSM/Centro de Ciências Rurais/ Departamento de Engenharia Rural/Laboratório de Geomática, 2007. 319p.

GIRARDELLO, V.C.; AMADO, T.J.C.; NICOLOSO, R.S.; HORBE, T.A.N.; FERREIRA, A.O.; TABALDI, F.M. \& LANZANOVA, M.E. Alterações nos atributos físicos de um Latossolo Vermelho sob plantio direto induzida por diferentes tipos de escarificadores e o rendimento da soja. R. Bras. Ci. Solo, 35:2115-2126, 2011.

HAMZA, M.A. \& ANDERSON, W.K. Soil compaction in cropping systems: A review of the nature, causes and possible solutions. Soil Till. Res., 82:121-145, 2005.

KLEIN, V.A. \& LIBARDI, P.L. A faixa de umidade menos limitante ao crescimento vegetal e a sua relação com a densidade do solo ao longo de um perfil de um Latossolo Roxo. Ci. Rural, 30:959-964, 2000. 
KLEIN, V.A. \& CAMARA, R.K. Rendimento da soja e intervalo hídrico ótimo em Latossolo Vermelho sob plantio direto escarificado. R. Bras. Ci. Solo, 31:221-227, 2007.

KLEIN, V.A.; VIEIRA, M.L.; DURIGON, F.F.; MASSING, J.P. \& FÁVERO, F. Porosidade de aeração de um Latossolo Vermelho e rendimento de trigo em plantio direto escarificado. Ci. Rural, 38:365-371, 2008.

MENEGATTI, L.A.A. \& MOLIN, J.P. Remoção de erros em mapas de produtividade via filtragem de dados brutos. $R$. Bras. Eng. Agríc. Amb., 8:126-134, 2004.

MOLIN, J.P.; MASCARIN, L.S. \& VIEIRA JUNIOR, P.A. Avaliação de intervenções em unidades de aplicação localizada de fertilizantes e de populações de milho. Eng. Agríc., 26:528-536, 2006.

NICOLOSO, R.S.; AMADO, T.J.C.; SCHNEIDER, S.; LANZANOVA, M.E.; GIRARDELLO, V.C. \& BRAGAGNOLO, J. Eficiência da escarificação mecânica e biológica na melhoria dos atributos físicos de um Latossolo muito argiloso e no incremento do rendimento de soja. R. Bras. Ci. Solo, 32:723-1734, 2008.

NIMER, E. Climatologia do Brasil. 2.ed. Rio de Janeiro, IBGE, Departamento de Recursos Naturais e Estudos Ambientais, 1989. 442p.

OLIVEIRA, M.L.; RUIZ, H.A.; COSTA, L.M. \& SCHAEFER, C.E.G.R. Flutuações de temperatura e umidade do solo em resposta à cobertura vegetal. R. Bras. Eng. Agríc. Amb., 9:535-539, 2005.

PIVETTA, L.A.; CASTOLDI, G.; SANTOS, G.C. \& ROSOLEM, C.A. Crescimento e atividade de raízes de soja em função do sistema de produção. Pesq. Agropec. Bras., 46:1547$1554,2011$.

REICHERT, J.M.; REINERT, D.J. \& BRAIDA, J.A. Qualidade dos solos e sustentabilidade de sistemas agrícolas. Ci. Amb., 27:29-48, 2003.

RICHART, A.; TAVARES FILHO, J.; BRITO, O.R.; LLANILLO, R.F. \& FERREIRA, R. Compactação do solo: Causas e efeitos. Semina: Ci. Agrár., 26:321-344, 2005.

ROQUE, M.W.; MATSURA, E.E.; SOUZAZ.M.; BIZARI, D.R. \& SOUZA, A.L. Correlação linear e espacial entre a resistência do solo ao penetrômetro e a produtividade do feijoeiro irrigado. R. Bras. Ci. Solo, 32:1827-1835, 2008.

ROSOLEM, C.A.; FOLONI, J.S.S. \& TIRITAN, C.S. Root growth and nutrient accumulation in cover crops as affected by soil compaction. Soil Till. Res., 65:109-115, 2002.
SANTI, A.L.; AMADO, T.J.C.; CHERUBIN, M.R.; MARTIN, T.N.; PIRES, J.L.; DELLA FLORA, L.P. \& BASSO, J.C. Análise de componentes principais de atributos químicos e físicos do solo limitante à produtividade de grãos. Pesq. Agropec. Bras., 47:1346-1357, 2012.

SANTOS, H.G.; JACOMINE, P.K.T.; ANJOS, L.H.C.; OLIVEIRA, V.A.; OLIVEIRA, J.B.; COELHO, M.R.; LUMBRERAS, J.F. \& CUNHA, T.J.F., eds. Sistema brasileiro de classificação de solos. 2.ed. Rio de Janeiro, Embrapa Solos, 2006. 306p.

SECCO, D. Estados de compactação de dois Latossolos sob plantio direto e suas implicações no comportamento mecânico e na produtividade de culturas. Santa Maria, Universidade Federal de Santa Maria, 2003. 108p. (Tese de Doutorado)

SECCO, D.; ROS, C.O.; SECCO, J.K. \& FIORIN, J.E. Atributos físicos e produtividade de culturas em um Latossolo Vermelho argiloso sob diferentes sistemas manejos. R. Bras. Ci. Solo, 29:407-414, 2005.

SECCO, D.; REINERT, D.J.; REICHERT, J.M. \& SILVA, V.R. Atributos físicos e rendimento de grãos de trigo, soja e milho em dois Latossolos compactados e escarificados. Ci. Rural, 39:58-64, 2009.

SILVA, V.R.; REICHERT, J.M. \& REINERT, D.J. Variabilidade espacial da resistência do solo à penetração em plantio direto. Ci. Rural, 34:399-406, 2004.

SUZUKI, L.E.A.S.; REICHERT, J.M.; REINERT, D.J. \& LIMA, C.L.R. Grau de compactação, propriedades físicas e rendimento de culturas em Latossolo e Argissolo. Pesq. Agropec. Bras., 42:1159-1167, 2007.

STONE, L.F.; GUIMARÃES, C.M. \& MOREIRA, J.A.A. Compactação do solo na cultura do feijoeiro - I: Efeitos nas propriedades físico-hídricas do solo. R. Bras. Eng. Agríc. Amb., 6:207-212, 2002.

TAVARES FILHO, J. \& TESSIER, D. Compressibility of Oxisol aggregates under no-till in response to soil water potential. R. Bras. Ci. Solo, 33:1525-1533, 2009.

TAYLOR, H.M. \& BRAR, G.S. Effect of soil compaction on root development. Soil Till. Res., 19:111-119, 1991.

TORMENA, C.A. \& ROLOFF, G. Dinâmica da resistência à penetração de um solo sob plantio direto. R. Bras. Ci. Solo, 20:333-339, 1996.

TORMENA, C.A.; SILVA, A.P. \& LIBARDI, P.D. Caracterização do intervalo hídrico ótimo de um Latossolo Roxo sob plantio direto. R. Bras. Ci. Solo, 22:573-581, 1998. 